\author{
Анна Трофимова \\ Казанский (Приволжский) федеральный университет (Казань, Россия)
}

\title{
О роли русских предлогов в структурировании пространства
}

Пространство как универсальная категория человеческого сознания и культуры является предметом изучения многих наук, в том числе и лингвистики, которая на материале языковых единиц рассматривает особенности моделирования человеком пространства. К числу таких единиц относятся, в частности, предлоги. Для исследования были выбраны базовые предлоги, участвующие в формировании пространственного видения окружающего мира: предлоги, соответствующие горизонтальному направлению (перед, за), вертикальному (nод, над), а также предлоги пересечения двух плоскостей $(в, \mu a)$. Выбор данных предлогов обусловлен тем, что они формировались в ранний период развития языка и отражают древнее мировосприятие, элементы которого сохранились в сознании современного человека на уровне архетипов. Мы будем рассматривать семантику данных предлогов с позиций когнитивного подхода, то есть попытаемся ответить на вопрос, как в значениях предлогов отражены результаты познавательных процессов человека, его восприятия мира.

Сейчас все больше исследователей склоняются к тому, что «любое знание существует в виде ментальных репрезентаций», а «язык формируется для объективации этих репрезентаций» (Кубрякова 2012: 106). Наиболее четко эта мысль выражена в теории ментальной модели Ф. Джонсона-Лэрда. Под ментальной моделью понимается промежуточная структура, которую человек строит при восприятии вербальной информации (в частности, о пространстве), некий «интерфейс между языком и миром» (Coventry, Carmichael, Garrod 1994: 290). Таким образом, мы вслед за Ф. Джонсоном-Лэрдом исходим из того, что семантика предлога «является конструкцией человеческого разума, а не результатом прямого соотнесения с объективными отношениями в реальном мире» (Johnson-Laird 1983: 197).

Отметим, что категория пространства формировалась в очень древний период развития человечества и опиралась на мифологическое мышление, на наивную картину мира, под воздействием которой формировались общие знания и представления человека о мире, отраженные в языковой картине 
мира. При этом категоризация предметов в пространстве носит национально-специфический характер, поэтому «у людей, говорящих на разных языках, неодинаковы способы концептуализации, категоризации, классификации, структурирования и описания пространственных объектов, их свойств и отношений» (Тханг 1993: 182).

Лингвисты, исследующие пространственные предлоги, называют разные признаки, определяющие употребление того или иного предлога:

1. геометрические характеристики пространственной сцены:

- мерность предмета (категоризация предмета как точки/плоскости/ контейнера) (Jackendoff, Landau 1991);

- особенности взаимодействия предметов в пространственной сцене (горизонтальное или вертикальное положение предметов; наличие или отсутствие контакта между ними; статичность или динамичность их взаимодействия и др.) (Всеволодова, Владимирский 1982; Рахилина 2008: 51-54);

2. негеометрические (функциональные) характеристики пространственной сцены: содержание, поддержка, заключение, контроль и др. (Coventry, Carmichael, Garrod 1994; Johnson-Laird 1983: 195-197; Маляр 2001; Селиверстова 2004).

Проанализировав зафиксированную в словарях семантику пространственных предлогов с учетом названных подходов, мы попытаемся построить когнитивные модели предлогов, опирающиеся на значимые для русской языковой картины мира пространственные параметры. Для выявления ментальных характеристик пространственных предлогов и пространственного мышления в целом мы будем привлекать также диалектный материал.

Строение когнитивной модели пространственных предлогов схоже со структурой фонемы. И. А. Бодуэн де Куртенэ понимал под фонемой «ту сумму антропофонических свойств, которая представляют собой неделимое единство» (Бодуэн де Куртенэ 1963: 120), то есть «пучок различительных признаков» в понимании представителей Пражской фонологической школы. Эти признаки активизируются в оппозициях - противопоставлениях, основанных на одном различительном признаке. В основе когнитивной модели русских пространственных предлогов, передающих взаимоотношения между объектами, лежат следующие дифференциальные признаки:

1. статика - динамика взаимодействия объектов;

2. контактность - дистактность положения объектов;

3. горизонталь - вертикаль зрительного восприятия объектов;

4. местоположение одного объекта относительно другого объекта (впереди - позади, выше - ниже, внутри - вне).

В контексте могут функционировать не все дифференциальные признаки предлога, а только один или два. В некоторых случаях, так же как и в оппозиции фонем, дифференциальные признаки когнитивной модели предлога могут нейтрализоваться, то есть предлог может использоваться для обозначения оппозиционных значений. 
Следует отметить, что среди дифференциальных признаков нет оппозиции объект - субъект, связанной с понятием одушевленности, поскольку для русского языкового сознания она не является существенной (интересно заметить, что эта оппозиция значима, в частности, в китайской языковой картине мира). В статике предлоги способны передавать одно и то же значение, употребляясь как с одушевленными, так и с неодушевленными существительными: человек лежит на кровати - сумка лежит на кровати. Определенную значимость данная оппозиция приобретает при описании динамических моделей с глаголами встать, поставить, лечь, положить и пр., где данное действие обязательно осуществляется одушевленным объектом.

Рассмотрим когнитивную модель предлога перед. Данный предлог имеет следующий набор различительных признаков ${ }^{1}$ :

1. статика + динамика (машина стоит перед домом - поставить вазу перед книгами);

2. дистактность (положить книгу перед собой - ср.: заложить руки за спину);

3. горизонталь (стоять перед домом - ср.: стоять под навесом);

4. впереди другого объекта, вне, ниже + выше (передо мной стоит стена - передо мной раскинулись поля).

Предлог за может выражать как статичные, так и динамичные отношения между предметом и поверхностью, но в этом случае полной нейтрализации оппозиции не происходит, поскольку дифференциация проходит по падежу: статика выражается конструкцией зa + T.n., динамика - зa+B.n. Кроме того, предлог за чаще используется для передачи дистактного характера отношений между предметом и поверхностью, однако в некоторых контекстах он может быть интерпретирован как указывающий на соприкосновение предмета с поверхностью (заложсить руки за спину). Таким образом, когнитивная модель предлога за имеет следующий вид:

1. статика + динамика (жить за рекой-уехать за реку);

2. дистактность + контактность (жить за рекой - положить подушку за спину);

3. горизонталь (стоять за домом - ср.: стоять под навесом);

4. позади объекта, вне, выше (картина висит за моей спиной).

Когнитивная модель предлога над:

1. статика + динамика (картина висит над столом - повесить картину над столом);

2. дистактность (стоять над столом - ср.: лежать на столе);

3. вертикаль + горизонталь (над болотом летали комары - дом стоит над озером);

Жирным шрифтом выделены дифференциальные, оппозиционные признаки, определяющие специфику предлога; знаком + характеризуются признаки, нейтрализующиеся в определенных ситуациях; знаком * отмечены диалектные значения предлога. 
4. выше + ниже*, вне, впереди + позади (дом стоит над озером - ночевать над сырым дубом*).

Когнитивная модель предлога под:

1. статика + динамика (сумка лежит под кроватью - положить сумку под кровать);

2. дистактность + контактность (стоять под навесом - лежать под одеялом);

3. вертикаль + горизонталь (сумка лежит под кроватью - жить под горой);

4. ниже объекта + выше*, вне (стоять под дождем - прямо под домами как молонья сиганет!), впереди* (стакан ставлю под собой).

Когнитивная модель предлога в:

1. статика + динамика (вещи лежат в шкафу - положить вещуи в шкаф);

2. контактность + дистактность (мебель в чехлах - поехать в город);

3. горизонталь + вертикаль (дыра в стене - дыра в полу);

4. внутри + вне (о территории) (лежать в сумке-лежать в поле).

Когнитивная модель предлога на:

1. статика + динамика (сидеть на стуле - посадить ребенка на стул);

2. контактность (на столе - ср.: над столом);

3. горизонталь + вертикаль (положить книги на стол - повесить картину на стену);

4. выше, впереди (книга на столе, картина на стене); вне + внутри (о территории) (на коробке - на заводе).

Таким образом, данные модели четко демонстрируют слабую дифференциацию пространства в русском языке, о чем свидетельствует частая нейтрализация дифференциальных признаков и что указывает на архаичность языковой картины мира. Так, базовые пространственные предлоги совмещают в себе следующие характеристики:

1. как статическое, так и динамическое взаимодействие объектов, которое определяется исключительно формой глагола или формой глагола и падежом (картина висит над столом - повесить картину над столом; жить за рекой - уехать за реку) (ср. более поздние предлоги из, по, от, которые передают только динамику отношений);

2. как горизонтальное, так и вертикальное зрительное восприятие (дыра в стене - дыра в полу; жить под горой - т.е. рядом, у подножия);

3. некоторые предлоги $(8, H a)$ не различают положение объекта внутри другого объекта и вне его (лежать в сумке - лежать в поле; на коробке - на заводе);

4. употребляются как с конкретными, так и с абстрактными существительными;

5. указывают на местоположение как лиц, так и предметов.

Значимым фактором является зрительность восприятия, поэтому предлог перед имеет больше всего дифференциальных признаков (этот фраг- 
мент пространства хорошо просматривается). Трудно подвергаемые зрительному восприятию фрагменты пространства с предлогами за, в крайне слабо дифференцированы.

Предлоги, описывающие вертикальное пространственное местоположение объектов, дифференцированы слабее предлогов, описывающих преобладание горизонтального местоположения, что также указывает на архаичность базовых характеристик русской языковой картины мира. Интересно отметить, что в говорах предлог под может обозначать расположение выше, а предлог над - расположение ниже.

Значимой для русского пространственного восприятия является оппозиция контактность - дистактность расположения объектов; именно по данному параметру различаются предлоги над и на, в остальном имеющие одинаковый набор признаков. Значимость оппозиции контактность - дистактность расположения обусловлена восприятием объектов в пространстве не сверху (как, например, в китайской картине мира), а сбоку, поскольку только такой взгляд позволяет увидеть наличие или отсутствие контакта между предметами. На моделирование пространства как горизонтальной структуры указывает также бо́льшая дифференцированность предлогов, описывающих горизонтальное местоположение объектов, по сравнению с предлогами, описывающими вертикальное положение. Такой взгляд отражает ключевое для русской культуры понятие пути, движение вперед. На преобладание горизонтального видения пространства неоднократно обращал внимание Г. Гачев, отметивший, что само слово пространство связано со словами сторона, страна, странники, странствия, в связи с чем поиски счастья и мотив дороги становятся ведущими в русской литературе (Гачев 1988: 257-258).

Таким образом, русское моделирование пространства отражает архетипические представления, которые заключаются в плоскостном восприятии пространства (двумерном, а не трехмерном), слабой дифференцированности положения объектов по вертикали, нерасчленении лиц и предметов, конкретных объектов и абстрактных понятий при описании пространственных сцен.

\section{Литература}

Бодуэн де Куртенэ И. А. (1963), Избранные труды по общему языкознанию, т. 1, Москва, $384 \mathrm{c}$.

Всеволодова М. В., Владимирский Е. Ю. (1982), Способы выражения пространственных отночений в современном русском языке, Москва, $264 \mathrm{c}$.

Гачев Г. Д. (1988), Начиональные образы мира, Москва, 445 с.

Кубрякова Е. С. (2012), В поисках сущности языка: Когнитивные исследования, Москва, $208 \mathrm{c}$.

Маляр Т. Н. (2001), Концептуализация пространства и семантика английских пространственных предлогов и наречий, Дис. ... Д-ра филол. наук, Москва, 389 с. 
Рахилина Е. В. (2008), Когнитивный анализ предметных имен: семантика и сочетаемость, Москва, 416 с.

Селиверстова О. Н. (2004), Русские пространственно-дистанционные предлоги и наречия, [в:] О. Н. Селиверстова, Труды по семантике, Москва, с. 719-930.

Тханг Л. Т. (1993), Пространственная модель мира: когниция, культура, этнопсихология (на материале вьетнамского и русского языков), Дис. ... д-ра филол. наук, Москва, 304 с.

Coventry K. R., Carmichael R., Garrod S. (1994), Spatial prepositions, object-specific function and task requirements, Journal of Semantics, Vol. 11, p. 289-309.

Jackendoff R., Landau B. (1991), Spatial Language and Spatial Cognition, «Bridges between Psychology and Linguistics. A Swarthmore Festschrift for Lila Gleitman», Hillsdale (N. J.), p. $145-169$.

Johnson-Laird P. N. (1983), Mental models: Towards a cognitive science of language, inference, and consciousness, Cambridge, 513 p.

Anna Trofimova

On the role of Russian prepositions in the structuring of space

Summary

Using the example of the spatial prepositions przed (in front of), $z a$ (behind), pod (under), nad (over), $w$ (in) and $n a$ (on), this paper considers the features of the modeling of space by native Russian speakers. The prepositions' meanings fixed in dictionaries are analyzed from the standpoint of the cognitive approach. To reveal mental characteristics of the spatial prepositions, dialect material is being examined. A brief review of the main approaches to the study of spatial prepositions is given. As a result, cognitive models of the spatial prepositions are constructed based on the parameters significant for the Russian linguistic world-image. The distinctive features underlying the cognitive model are the following: static or dynamic interaction between objects; presence or absence of the contact between them; horizontal or vertical position; location of objects relative to each other (in front / behind, above/below, inside/outside). The conclusion is that the Russian modeling of space reflects the peculiarities of the ancient world-view: two-dimensional perception of space; weak differentiation of vertical positions; absence of differentiation between persons and things as well as between specific objects and abstract concepts in describing spatial scenes. 